\title{
DIGITAL TECHNOLOGIES IN SUPPLY CHAIN MANAGEMENT IN PRODUCTION
}

\author{
Roman Veynberg ${ }^{1}$, Marina Koslova $^{2}$, Gani Askarov ${ }^{3}$, Asan Bexultanov $^{4}$, Zarema \\ Yussupova ${ }^{3}$ \\ ${ }^{1}$ Plekhanov Russian University of Economics, 117997, Moscow, Russian Federation \\ ${ }^{2}$ Serikbayev East-Kazakhstan State Technical University, 070004, Ust-Kamenogorsk, \\ Kazakhstan \\ ${ }^{3}$ Al-Farabi Kazakh National University, 050040, 71, al-Farabi Ave, Almaty, Kazakhstan \\ ${ }^{4}$ Academy of Public Administration under the President of the Republic of Kazakhstan, Nur-Sultan, \\ Kazakhstan
}

\begin{abstract}
The article discusses the prospect of using digital technologies in supply chain management, as well as the main trends and features of the development of supply chain management at the plant. The article deals with issues related to the integration of blockchain technologies in the field of logistics and supply chain management. The article suggests using blockchain information technologies to optimize supply chain management processes in the context of enterprise virtualization and digital economy development. The study revealed the advantages of this approach over traditional business management technologies and logistics systems. The prospects for using blockchain technology in logistics and supply chain management are also analyzed.
\end{abstract}

\section{INTRODUCTION}

One of the main factors for promoting the country's economy is the development of digital technologies. Without information and communication technologies, it is impossible to improve the quality of life of the population. Today, the economy is undergoing various transformations and is striving for a new type, where digital technologies become the main tool for ee formation. the Internet economy in developing countries is growing at a rate of up to $25 \%$ per year, although no sector of the economy can even come close to this rate.

The rapid development of IT technologies has led to the creation of digital supply chains and their development. Digital supply chains help you personalize a product or service. It also makes it possible to adjust to the needs of consumers and reduce the financial costs of moving goods along the logistics chain.

* Corresponding author: veynberg@gmail.com 
To make accurate decisions, managers need access to real-time supply chain data. Digital technologies will help companies collect, analyze, integrate, and interpret highquality, up-to-date data. This data will be used to build automation, forecasting, and robotics-all innovations that will replace traditional supply chain management.

Leading companies are already using robots and artificial intelligence to digitize and automate time-consuming and repetitive processes, such as purchasing, invoicing, and debt calculation, as well as partially to work with customers. Predictive Analytics helps to predict more accurately the demand, and the company thus increase the efficiency of use of assets and provide convenience for customers at a reasonable price. Sensors that record the condition of machines in use allow you to make more accurate assumptions about possible breakdowns, and this reduces downtime. Blockchain has launched a revolution in the interaction of participants in flexible supply chains. Robots increase the productivity and profitability of warehouses and order fulfillment centers.

It is important to note that many logistics functions are automated through digital clientcontractor integrations, digital document management, and a digital archive of events and documents. A person has long been unable to compete with a machine in terms of data analysis and predictive risk calculation. It remains to wait a bit, when the digitized and robotic back office of the logistics Department of both the client and the contractor will take over most of the routine transport tasks.

\section{LITERATURE REVIEW}

In modern conditions, the organization of logistics processes in companies of various industries needs constant improvement. This is obvious, since logistics costs can be significant. For example, in the United States, logistics costs account for 10 to $15 \%$ of the cost of industrial products, and their share in the structure of gross domestic product reaches $8 \%$ [1]. Reducing logistics costs, increasing the efficiency and flexibility of supply chains significantly affects the performance of various companies. Therefore, the logistics sector is now becoming a powerful driver of development and increasing the competitiveness of companies [2]. There are various methods for improving the efficiency of supply chains, but one of the most promising today are methods that involve the use of digital technologies.

According to S. Harvier, an expert at the world economic forum, the modern world is on the threshold of a new digital age.other researchers believed that this era has already come.

Grant Waterfall, head of PwC's cybersecurity Department, spoke about the" basic eight " technologies that are changing our lives: artificial intelligence, augmented reality, blockchain, the Internet of things, 3D printing, virtual reality, robotics and drones. In his opinion, these technologies will totally transform many sectors of the economy: healthcare, energy, and, first of all, logistics.

Dmitry Kokurin believes that new digital technologies include the development of functionality in global communication and information flows in supply chains, and the most important innovation in this area is the ability to digitize key business processes (including logistics) supported by sensors, robotics, and content information. [3]

Bochkarev P. A. analyzed a critical analysis of the most popular ways to evaluate and ensure the reliability of supply chains, such as the way they are designed and developed to create efficient storage chains that evaluate the quality of logistics services based on a" perfect " model. According to the scientist, all these models are very descriptive and help to group and define business processes, which makes the logistics process a little easier, but they are not a specific solution, but are of a recommendatory nature. 
V. I. Sergeev believes that the optimization of supply chains is already widely supported by software tools (in particular, such companies-system integrators as SAP, Oracle, 1bmb Infor). This tool can use scenario modeling and simulation to determine the best possible supply chain. The author believes that the task should be to test a device that performs explicit algorithms and performs certain functions to ensure the reliability of supply chains.

According to PwC, as well as many people on the sidelines, it is logistics with all the above innovations that will provide us with some of the most fantastic changes in the near future. [4]

\section{METHODOLOGY}

Digital transmission chain management (SCM) is a new direction in the development of information integration. It has gained wide popularity. "Companies can gain competitive advantages (costs, delivery times, pre-sales preparation, time, and after-sales service) by managing the digital delivery chain. There have also been recent changes in business development and IT technologies in this industry. Using these solutions will help increase the level of collaboration and openness of the supply chain. This creates the basis for a modern logistics strategy such as CPFR, S \& OP, EDI, ECR, JIT, QR, or VMI that can be implemented, and additional benefits are created for effective management and development of supply chains."[5] Digital transmission chain management has some features, including:

1) a large amount of data (Big Data). Big Data allows you to optimize (receive, store, and use) information created by participants in the supply chain. And in the future, they are actively using them.

2) have a low cost of data processing technology. Such technologies do not require serious financial investments from the company, because they require little equipment and maximum coordination (participation) of all participating companies;

3) availability of automated integration. This significantly reduces the standard work, and all participants in the chain can get access to the necessary information. If necessary, they can edit, correct, or Supplement this information;

4) various technologies for human interaction. Such as: the Internet, as well as other programs that can improve decision-making efficiency by sending (providing) real-time information (feedback).

Blockchain plays an important role in digital supply chain management. In 2017, blockchain became one of the eight most effective technologies that can affect the company's business model. This is shown in pic. 1. [5] 


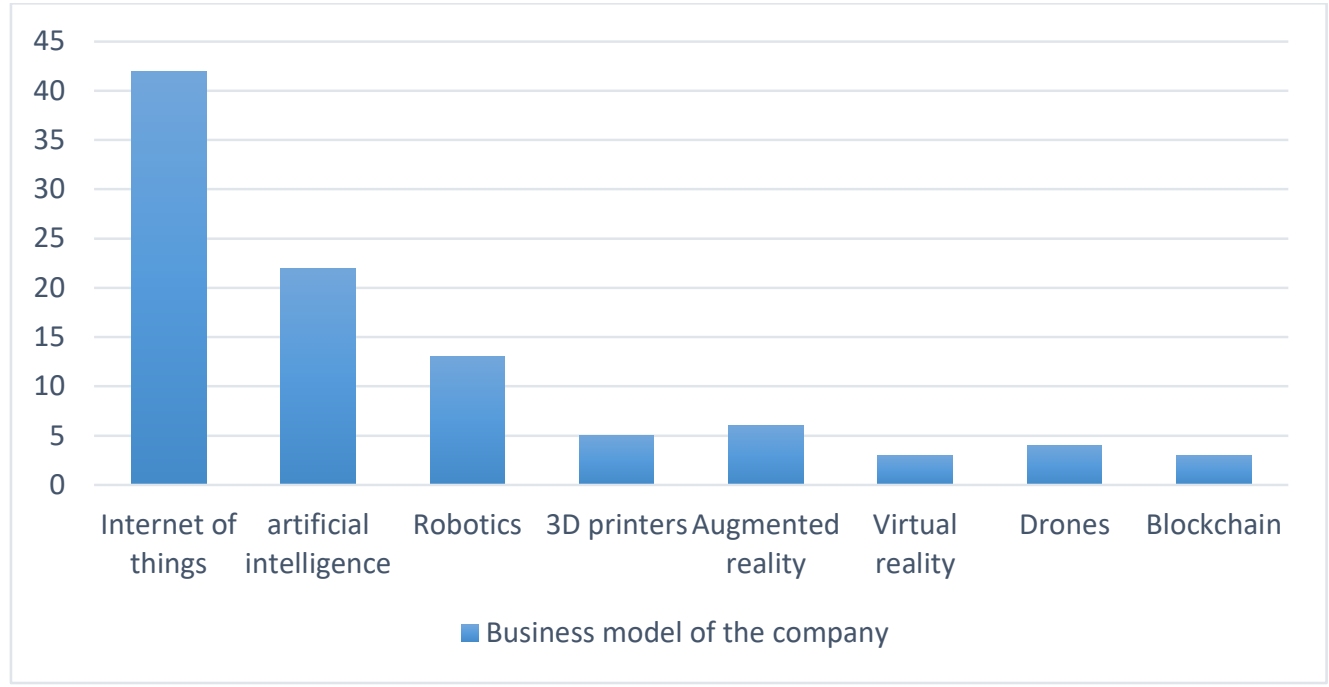

Pic.1 - rating of technologies by the degree of influence on the business model of enterprises

Blockchain is a multi-functional and multi-level information technology, generally designed for reliable accounting of various assets and transactions. This technology covers all areas of economic activity without exception and has many applications. These include: economic and financial; material and non-material transactions; accounting for government organizations and companies; supply chain management and supply chain management (SCM), and more. [6]

It is believed that the Creator of the technology of the blockchain is Satoshi Nakamoto who first presented it to cryptomelane bitcoin. Currently, blockchain technology is coming to the forefront in various areas of human activity, and many authors consider it in the field of logistics and supply chain management. Blockchain technologies are promising for the implementation of corporate information systems, because today isolated internal business processes in the back office prevail, which are extremely complex and confusing. [7]it is Obvious that in the modern world, blockchain technologies are necessary because of multiple interactions in data exchange and storage. When using the blockchain, the relationship is to create transfer documents and track the cargo by introducing new items. this block stores data about the cargo itself (its quantity, transportation time, quality of the delivered goods, costs, etc.) and inventory. "Such a database can not be fake or hacked according to the developers, which gives it undeniable advantages over other Internet technologies for recording and storing information, and the blockchain technology also provides a certain structure for recording and recording data, which standardizes the execution of various operations." [8]

Creating a blockchain is based on three main principles that can be used to build a digital supply chain:

* distribution - data is stored by all users of the network / platform and does not require the creation of a centralized data center;

- transparency - transaction data may be visible to all participants of the process / system;

* security - each transaction and its data are protected by encryption, as well as access keys that contain from 28 to 36 different characters.

The process of implementing blockchain technology in supply chain management is shown in figure 1. [9] 


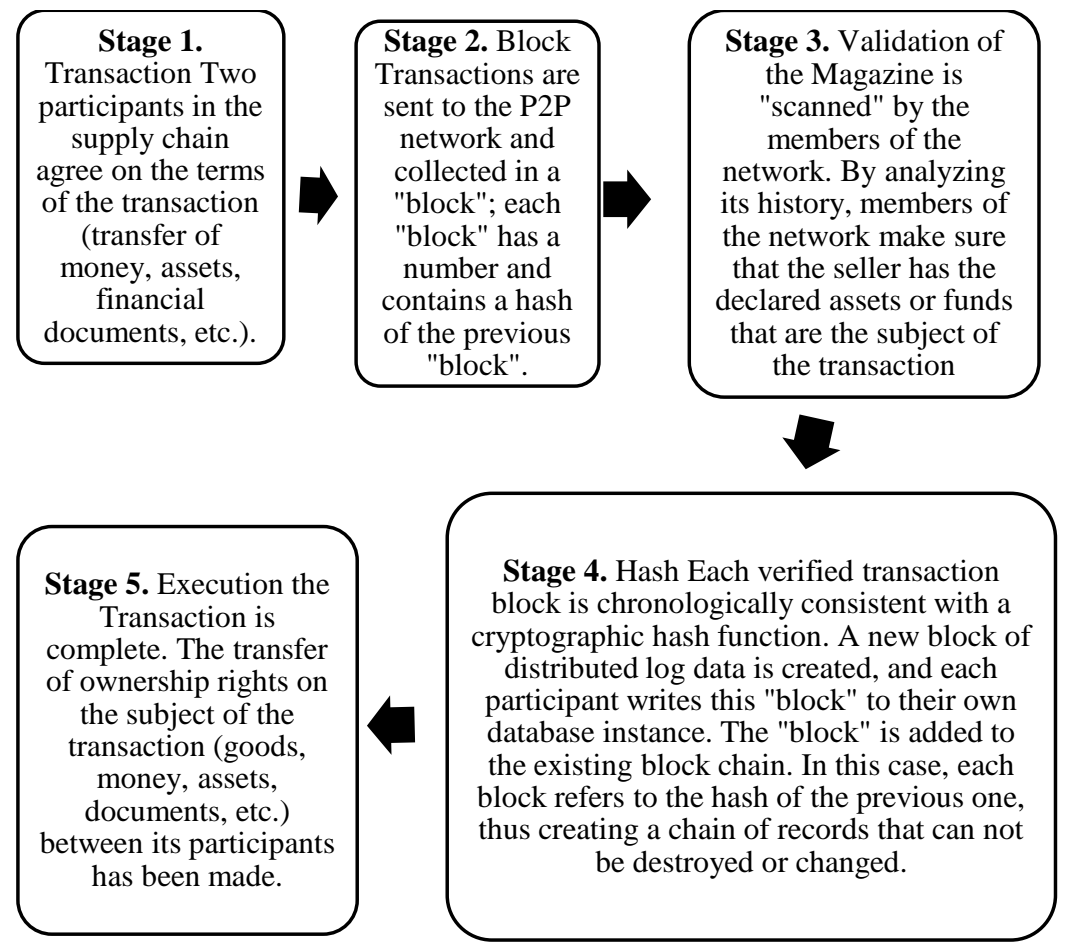

Fig. 1-Stages of implementation of the blockchain technology in the ADC

The key advantage of Blockchain over traditional financial or other operations is the absence of intermediaries. Any transaction with cash, documents and other assets today requires intermediaries and controllers, regulators. The authenticity of such a financial transaction is confirmed through commercial banks and other non-banking institutions. The blockchain is completely decentralized and independent, so all transactions are controlled by the participants themselves, which simplifies a significant part of the procedures, and also allows you to get rid of intermediaries. Table 1 provides a comparative description of the process of interaction between suppliers and end users in the logistics chain in the traditional transaction model and based on the blockchain. [10] as you can see, blockchain is a tool for solving one of the most difficult problems of coordination between organizations, namely, ensuring the flow of information and the trust of the counterparty in the supply chain. The supply chain, as a complex ecosystem that requires the distribution of responsibilities between Contracting parties in the execution of contracts that arise during its operation, has all the conditions for the implementation of this technology. [11]All participants in the logistics ecosystem are members of the supply chain, the main of which are manufacturers, consumers, distributors, retail customers, processors, suppliers, transport companies, as well as all suppliers who have access rights and keys to the system. All parties of the ecosystem can interact independently from each other without intermediaries. This distinguishes this system from the centralized transaction model that was discussed earlier. All actions of supply chain participants that are part of the ecosystem are recorded in the General Ledger by adding entries to the distributed sales network. At the same time, the confidentiality of the work is ensured and all transactions are visible and secure, since they are checked and verified by all participants in the system. Thus, consensus is achieved by checking the transaction. A key feature of blockchain-based supply chain participants is the use of smart contracts, the implementation of which does not require the mediation of 
financial institutions, and trading conditions are part of transactions and are performed with operations. [12]

Table 1-Comparative characteristics of the process of interaction between suppliers and end users in the logistics chain

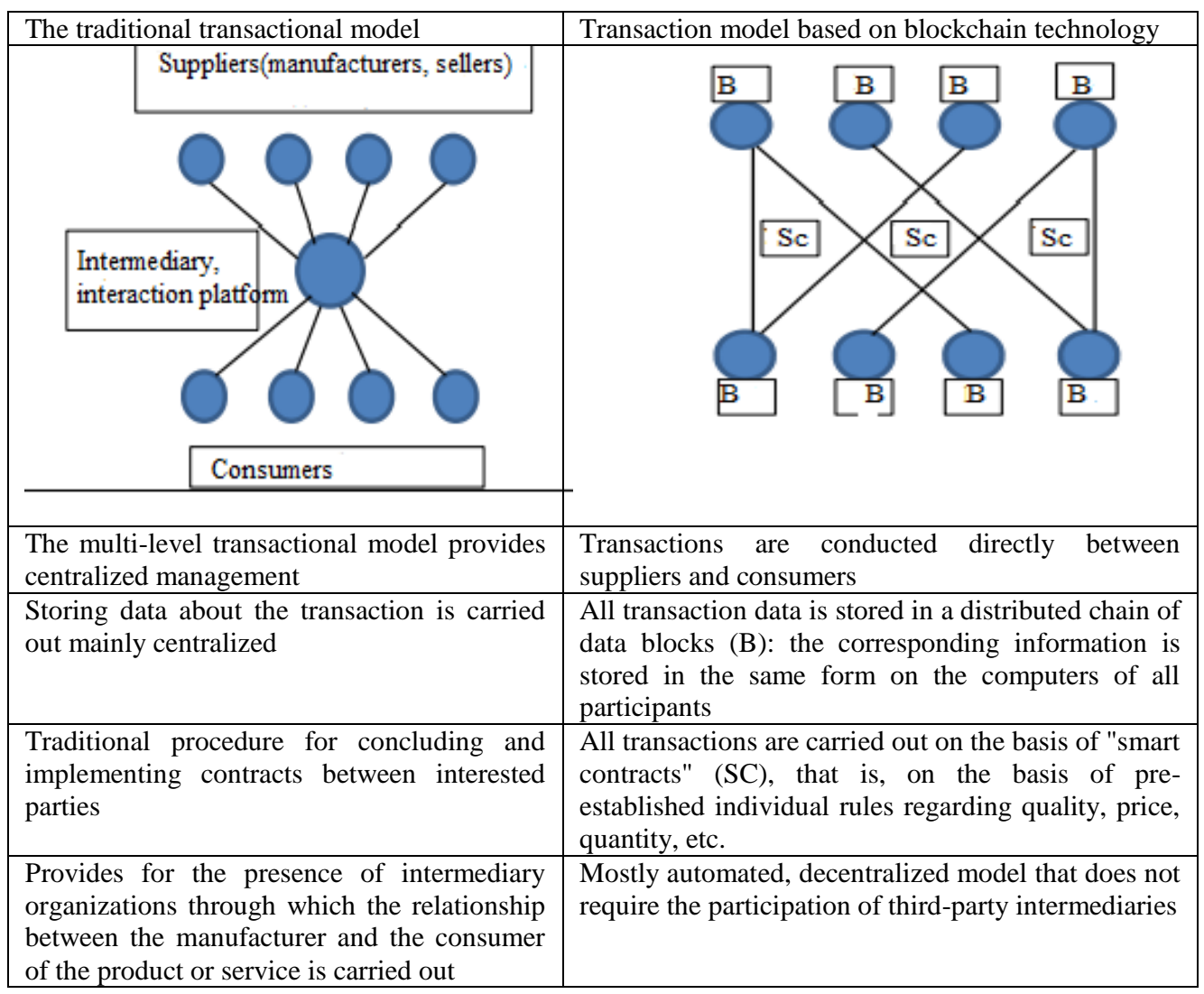

Another advantage of using blockchain technology in the SCP is the fact that this technology can significantly reduce the share of counterfeit products in the Kazakh market. How does it work? The entire product lifecycle can be tracked through the clent chain, which is open to all participants in the supply chain, given that they work with the blockchain. If all industrial companies implement these technologies, all counterfeit goods will be easily destroyed. This is important because the Kazakh market is literally filled with fake products from China, especially tobacco and alcohol. This change is due to increased taxes and a large number of counterfeit goods (in particular, tobacco) that are imported from China. The introduction of blockchain technology by an industrial company automatically protects against fraud - in the end, fraud cannot be documented. [13]

Today, even the largest organizations lack the capacity, resources, and knowledge to integrate information in their supply chains. Typically, the structure of a supply chain network consists of several links (contractors) that depend on content, information, and financial flows. All this flow can be managed through a single information system, in which participants in the supply chain have the same rights as the widespread ones. Speaking specifically about the industrial sector, the scope of blockchain technology is wide: from quality control to supporting all product life cycles, ensuring reliability and the 
flow of participants across all supply chains. The use of blockchain ensures rapid integration of information between supply chain participants and transparency of their communication. [14]

Using the technology of the Blockchain, it is possible to optimize the information flow:

organization of a single information space;

- $\quad$ обнаружение detection of all transport documents in the public domain;

- $\quad$ to reduce the processing time of documents;

- $\quad$ reducing the time spent by the tax office;

- holding immediate insurance of the goods;

- $\quad$ submission of documents to the customs authorities of the headquarters.

Despite the fact that blockchain technology has a huge potential, it still has some limitations and problems:

1. Formation of new systems

Systems specially designed to organize the supply chain are unable to adapt to the environment based on the blockchain. Reconstruction of business infrastructure and business processes is an important event that can disrupt operations and attract resources from other projects. Therefore, senior management should not make a decision about this type of investment before it is widely accepted by other major players in the sector.

2. Finding partners on Board

Partners involved in the supply chain should also be ready to join the blockchain technology. Although organizations still benefit from blockchain being involved in some part of the process, they will not be able to fully use their capabilities in the event of a disagreement. Moreover, transparency is not what all companies want.

\section{Change control}

Once the blockchain system is implemented, businesses will need to distribute it to their employees. The change management plan should take into account what the blockchain is, how it will improve personal responsibilities at work, and how to work with new systems. The current curriculum may focus on new features or innovations in blockchain technology, but it certainly requires time and resources. [15]

An example of effective use of blockchain technology in logistics/SCP is food security. According to annual estimates of diseases recorded by the world health organization, one in ten people get sick worldwide, and about 20,000 people die as a result of contaminated food. Today, retailers are looking to use blockchain technology to provide customers with reliable information about food products, improve the traceability of their progress in the food supply chain, and increase consumer confidence in their stores. To this end, IBM and the global retail chain Walmart initiated the use of blockchain technology in the development of a distributed register of transparent food tracking in supply chains. The blockchain allows users to track shipments of meat, perishables, and other products from suppliers to Walmart stores. The blockchain, along with the sensor system, allows a retail retailer to track deliveries quickly, efficiently and reliably. [16]

The largest European port in Rotterdam, thanks to the efforts of the municipal authorities, opened the BlockLab research laboratory, which began to apply applied research in the field of distributed register technologies for logistics processes and effective traffic management. The first steps of the laboratory are aimed at launching block applications for warehouse financing of the logistics sector.

The British company Provenience offers an extensive way to manage fish supplies using blockchain technology. Now the fish market is recorded on paper, and the tags on it help to track the fish. The idea behind Provenience is that fishermen will need to send an SMS to register their catch in the blockchain. The digital batch code is sent to the fish supplier, and any subsequent iteration (such as processing fish) is also written to the string. The smartphone then gets access to the fish source and supply chain for the end customer or 
consumer in the store or restaurant. The service is tested by a group of food cooperatives, the trial period will last until the end of the year. Using the technology increases the cost of fish by a few cents, so if this idea produces the expected results, it can initially only be applied to expensive varieties of fish. [17]

Specialists in offshore projects of Gazprom Neft PJSC and Gazpromneft-Supply LLC tested blockchain and Internet of things technologies in logistics of material and technical resources. For the implementation of the pilot project, a difficult place was chosen from the point of view of logistics. The tests were carried out by a separate division of Gazprom Neft - the Department of offshore project development and Gazpromneft-Supply. The project provided logistics services for the supply of shut-off valves purchased from the Gazprom oil shelf for offshore fixed platforms (MTZNA) from the Prirazlomnoye sea in the Pechora sea. The pilot project was implemented as follows. Radio frequency tags (RFID) and satellite positioning (GPS) were installed on the valves. A document with delivery information was generated when reading RFID tags from a factory in Veliky Novgorod. The GPS sensor allows you to monitor the movement of cargo to the warehouse base in Murmansk, its speed, number and duration of stops on the road. All data received from the devices was registered under the smart contract and projected into the blockchain. The chosen scheme is best suited for implementing the "Internet of things" concept, since centralized technologies for the Internet of things are not very suitable due to complexity, complexity of scaling, and low security. [18]

\section{RESULTS}

Logistics ceases to be a related activity of the company and becomes part of its value proposition. Many logistics functions are automated through digital client-contractor integrations, digital document management, and a digital archive of events and documents.

The era of hybrid supply chain management is coming. The world of logistics, like many other industries, in my opinion, will be divided into two types of players:

- Foundries - "stamping plants" - carry out routine work, both on the side of clients and on the side of contractors working in highly competitive markets, where the main way to survive is to save on scale. In our case, these are sea container carriers, railway and road transport companies, freight forwarders and niche service providers: booking agents, customs brokers, surveyors, etc. [19]

- Fabless — "factory-free companies" - are responsible for the design of logistics networks, optimization of existing transport organization schemes.

A digital transformation company sets priorities along the way. When developing a strategy, CDTO selects projects of high priority. Supply chain management is not the primary focus of digital transformation Directors. And it all depends on the fact that there is a gap in competencies: techies do not understand anything about logistics, and logisticians are as far as possible from all this technological hype. According to KMDA research, logisticians generally consider their progress in digital transformation insignificant and find the digital channel unimportant for their customers. [20]

\section{CONCLUSION}

The modern world requires comprehensive and integrated development of state institutions and business. This makes it increasingly clear that our company's activities require the introduction of modern methods of organizing processes, such as the digital economy. 
Logistics, which is a complex and multi-step process, is an integral part of most trade and market relations, and logistics needs to be constantly improved to ensure the effectiveness of the economic processes in which it is involved. It technologies and the Internet environment can be one of these necessary transformations. In particular, the use of blockchain technology in logistics can give a good incentive to fulfill the tasks set by the state today. This article covered topics such as digital supply chain management and the scope of block chain technology, as well as the challenges of implementing block chain technology in logistics. The transformation of supply chain management is an integral part of the digital transformation of the entire global economy.

Structural changes in the logistics industry are not so much related to the technical methods of order execution, but rather to the transformation of the decision-making process and the speed of adaptation of the system to various changes in the overall strategy of the company and the external environment.

The main purpose of this study is to analyze the possibility of developing blockchain technology in supply chain management, as well as the prospects for further digitization of economic and business processes. In the digital economy blockchain logistics technology can help the world achieve transparency and security.

\section{REFERENCES}

1. Barkova, N. YU. Cifrovye tehnologii v upravlenii cepyami postavok industrii mody. Vestnik universiteta, (3) (2019).

2. Bochkarev, P. A. Upravlenie nadejnost'yu cepei postavok v logistike snabjeniya (Doctoral dissertation, Bochkarev Pavel Andreevich.-SPb.: NIU VSHE, $155 \mathrm{c}$, 2015.

3. Bukrina, E. V. Industrial'nyi internet veschei, seti $5 \mathrm{~g}$, blokchein-tehnologii sovremennogo innovacionnogo razvitiya. In Sbornik statei podgotovlen na osnove dokladov Mejdunarodnoi nauchno-prakticheskoi konferencii «Nauka i innovacii v sovremennyh usloviyah», sostoyavsheisya 08 marta 2018 g. v g. Orenburg. (p. 108) (2018).

4. Ziyadin, S., Doszhan, R., Borodin, A., Omarova, A., Ilyas, A. The role of social media marketing in consumer behaviour/E3S Web of Conferences (2019)

5. Sergeev, V. I., \& Kokurin, D. I. Primenenie innovacionnoi tehnologii" Blokchein" v logistike i upravlenii cepyami postavok. Kreativnaya ekonomika, 12(2) (2018).

6. Suchilova, K. V., \& Greiz, G. M. PERSPEKTIVY PRIMENENIYA TEHNOLOGII BLOKCHEIN V LOGISTIKE I UPRAVLENII CEPYAMI POSTAVOK. In Forsait logistiki: buduschee logistiki glazami molodyh uchenyh (pp. 29-34) (2018).

7. Ukraincev, V. B., \& Ahohov, A. M. Tehnologiya blokchein v logistike: cifrovizaciya i perspektivy ispol'zovaniya. Logistika i upravlenie cepyami postavok, (6), 42-48 (2017).

8. Helo, P., \& Shamsuzzoha, A. H. M. Real-time supply chain-A blockchain architecture for project deliveries. Robotics and Computer-Integrated Manufacturing, 63, 101909 (2020).

9. Kawaguchi, N. Application of Blockchain to Supply Chain: Flexible Blockchain Technology. Procedia Computer Science, 164, 143-148 (2019). 
10. Kshetri, N. 1 Blockchain's roles in meeting key supply chain management objectives. International Journal of Information Management, 39, 80-89 (2018).

11. Lee, T., \& Nam, H. An empirical study on the impact of individual and organizational supply chain orientation on supply chain management. The Asian Journal of Shipping and Logistics, 32(4), 249-255 (2016).

12. Liu, Z., \& Li, Z. A blockchain-based framework of cross-border e-commerce supply chain. International Journal of Information Management, 102059 (2019).

13. Lintukangas, K., Kähkönen, A. K., \& Hallikas, J. The role of supply management innovativeness and supplier orientation in firms' sustainability performance. Journal of Purchasing and Supply Management, 25(4), 100558 (2019).

14. Nakamoto, S. Bitcoin: A peer-to-peer electronic cash system. Manubot (2019).

15. Schmidt, C. G., \& Wagner, S. M. Blockchain and supply chain relations: A transaction cost theory perspective. Journal of Purchasing and Supply Management, 25(4), 100552 (2019).

16. Wang, Z., Wang, T., Hu, H., Gong, J., Ren, X., \& Xiao, Q. Blockchain-based framework for improving supply chain traceability and information sharing in precast construction. Automation in Construction, 111, 103063 (2020).

17. Wamba, S. F., \& Queiroz, M. M. Blockchain in the operations and supply chain management: Benefits, challenges and future research opportunities. (2020).

18. Ziyadin, S., Suieubayeva, S., Utegenova, A. (2020) Lecture Notes in Networks and Systems 84. P. 408-415 DOI: 10.1007/978-3-030-27015-5_49

19. Yedilbayev, B., Kozhamkulova, Z., Abdikul, S., Tulebayeva, N. New models of road transport system, E3S Web of Conferences 2019

20. Sharapiyeva, M.D., Antoni, A., Yessenzhigitova, R. The impact of port transportlogistics infrastructure and lpi for economic growth: On the example of landlocked countries//Pomorstvo №1, P.63-75 2019.

21. Mutalimov V, Kovaleva I, Mikhaylov A, Stepanova D. Journal of Entrepreneurship Education, 23(1). (2020). 